\title{
Body mass index, dental caries and sugar intake in $2-5$ year-old preschoolers
}

\author{
Ronald Jefferson Martins', Suzely Adas Saliba Moimaz', Mirelli Ramiro Silva', \\ Orlando Saliba', Clea Adas Saliba Garbin ${ }^{1}$
}

${ }^{1}$ Universidade Estadual Paulista - UNESP, Faculty of Dentistry of Araçatuba, Department of Social and Preventive Dentistry, Araçatuba, SP, Brazil

\begin{abstract}
Aim: To determine the association between dental caries, Body Mass Index (BMI) and sugar intake in children attending primary school. Methods: A cross-sectional study was conducted with 91 children, with mean age of 3.9 years ( $\mathrm{sd}= \pm 1.0$ ), considering anthropometric measurements, according to standardized methodology of the Ministry of Health and occurrence of dental caries was recorded from clinical examinations (dmft). The sugar intake level was measured with a questionnaire that was applied to parents/caretakers of the children. The association of the variables was checked using a correlation with the Contingency $C$ coefficient test. Results: $33(36.3 \%)$ children were at risk for overweight, overweight or obese. Of these, $10(30.3 \%)$ had $\mathrm{dmft} \geq 1$. An association was found between sugar added to the bottle and child dmft (coeff. $C=0.5853$ and $p<0.0001$ ) and also with BMI (coeff. C $=0.5693$ and $p<0.0001$ ). There was no association between BMI and caries (chisquare $=0.1447$ and $p$-value $=0.7036$ ). Conclusions: It was concluded that there was a correlation between sugar intake and dmft and BMI, but not between caries and BMI.
\end{abstract}

Keywords: child, preschool; body mass index; dental caries; obesity.

\section{Introduction}

The World Health Organization (WHO) considers obesity one of the ten major public health problems in the world, classifying it as an epidemic of the $21^{\text {st }}$ century ${ }^{1}$. There are 300 million obese people worldwide, and among them 43 million children under five years of age who are overweight ${ }^{2}$.

Obesity in childhood is an alert to the public health, a serious and emergency issue because it tends to persist into adulthood, constituting a risk factor for the occurrence of several chronic diseases ${ }^{3-4}$. According to WHO, the high sugar consumption is a major cause of weight gain ${ }^{1}$.

As for obesity, the high frequency of intake of sugar-rich foods is closely related to the etiology of dental caries. Eating habits are key factors in these two diseases ${ }^{5}$.

It is essential to establish healthy practices and to monitor food and nutrition, especially in children 2 to 5 years of age, as in this period he or she starts adopting habits and behaviors, and a healthy diet is essential to ensure adequate growth and development of children ${ }^{4-6}$.

Although obesity theoretically is associated with tooth decay because these diseases present an etiological factor in common, the documentation of such associations is scarce and seemingly inconsistent. Population studies on childhood obesity associated with dental caries are scarce in Brazil. These surveys provide information about the actual state of health of the child population, providing subsidies to chart new directions to the Brazilian health system. 
In this context, the objective was to determine the association between dental caries, Body Mass Index (BMI) and sugar intake in children attending primary school in the countryside of Araçatuba, SP, Brazil.

\section{Material and methods}

The research protocol was approved by the Ethics Committee in Human Research, Araçatuba Dental School/UNESP (process FOA-01411/2011).

This was a population-based cross-sectional study and the sample consisted of all children aged 2 to 5 years enrolled in a charity institution that serves as a nursery and kindergarten in Araçatuba, SP, Brazil. None of the children presented either systemic or neurological conditions that could prevent them from taking part in the study. Only children whose parents/caretakers did not agree with the survey were excluded.

The codes and criteria for measuring $\mathrm{dmft}$ followed the guidelines of the $\mathrm{WHO}^{7}$. In order to evaluate Anthropometric assessment the team used the children's Body Mass Index (BMI). Weight and height taken from each child were transformed in the corresponding $\mathrm{z}$ scores by age and sex. Complying with the recommendations of the Brazilian Pediatric Association, thinness, normal weight, risk for overweight, overweight and obesity were defined according to the criteria percentile for weight and height related to each sex and age group ${ }^{8}$.

The data on sugar intake were obtained by a questionnaire administered to the parents/caregivers, with the following questions: (a) Do you put sugar in your child's milk? Giving a possibility to answer "yes" or "no". (B) What do you put in the bottle, besides milk? Giving a possibility to answer "the child does not use a bottle," "nothing" or if so, asked to specify the food that was added. (C) Do you put some sugary snack in the child's pacifier? Giving a possibility to answer "the child does not use a pacifier", "nothing" or if so also requested to specify what food was added.

A pilot study was performed with $10 \%$ of the research universe in a different primary school of the city that presented the same characteristics of the school where the research was made in order to train and calibrate the examiner and recorded the codes and criteria of the used indexes, in addition to the adequacy of the questionnaire.

Only one trained and calibrated researcher conducted the dental caries exams and took the height and weight of the children. The researcher was also responsible for applying the questions to the children's parents/caretakers.

The quality control of the data was performed by analysis of reproducibility of observations by the examiner and the calibration results were verified by analysis of agreement - kappa examiner, obtaining the value $\mathrm{k}=0.86$, indicating excellent agreement.

The BioEstat ${ }^{\circledR}$ software, version 5.3, was used to determine the association between the study variables using the nonparametric chi-square test of independence and Contingency Coefficient $\mathrm{C}$ for correlation, with decision level of $\alpha=0.05$.

\section{Results}

In the analyzed period the institution had a total of 125 preschool children aged 2 to 5 years. The population of the study consisted of $91(72.8 \%)$ children, 45 (49.5\%) girls and 46 $(50.5 \%)$ boys, whose parents/caretakers returned the filled-out survey forms as well as the consenting term of agreement. With respect to age, $4(4.4 \%)$ children were 2 years old, $37(40.7 \%)$ 3 years old, $11(12.1 \%) 4$ years old and $39(42.8 \%) 5$ years old. The average age was 3.9 years old $(\mathrm{sd}= \pm 1.0)$.

The average dmtf for this group was 0.80 , with a total of $30(33 \%)$ children with teeth affected by dental caries (Table 1).

Out of the studied children, $33(36.3 \%)$ were found in the BMI stratification (risk of overweight, overweight or obese) of most concern. Of these, $10(30.3 \%)$ had teeth with caries. However, the BMI classification was independent of the presence of dental caries, and no statistically significant association was found, as demonstrated by the chi-square test of independence for association (Table 2).

Regarding the survey, 16 (17.6\%) parents/caregivers stated they used sugar in their children's milk. Of the 50 (54.9\%) children who used pacifiers, only $5(10 \%)$ had sugar or honey added to them. Of the $76(83.5 \%)$ children who were bottle-fed, $45(59.2 \%)$ had sugary food added to milk.

The Contingency $\mathrm{C}$ correlation coefficient test was used to verify the magnitude of the associations between the variables of the survey, the anthropometric data and the clinical results. It was found that there was an association between sugary food added to the children's bottle and the ceo- $\mathrm{d}$ (coeff. $\mathrm{C}=0.5853$ and $\mathrm{p}$ $<0.0001$ ) and BMI indexes (coeff. $\mathrm{C}=0.5693$ and $\mathrm{p}<0.0001$ ).

There was also an association between sugar added to milk and dental caries (coeff. $\mathrm{C}=0.5500$ and $\mathrm{p}<0.0001$ ), but no association between sugar and BMI. In addition, no association between pacifier with sugar or honey and BMI or caries was found.

\section{Discussion}

Dental caries is a multifactorial disease that can be prevented, controlled, or even reversed, by means of prevention programs in the community, educational institutions and in the households. For prevention it is essential that the risk factors be known in order to be controlled. The disease is able to cause great destruction to the teeth, or even lead to teeth loss and may result in local, systemic, psychological and social complications ${ }^{9-10}$.

Data from the National Survey of Oral Health showed a dmft average of 2.43 for 5 year-olds, and $46.6 \%$ of children in Brazil were free of caries ${ }^{11}$. A dmft of 1.46 in average was detected in a survey conducted in another Brazilian city ${ }^{12}$. In the present study

Table 1- Number and percentage of preschoolers with respect to the degree of dmft index. Araçatuba, São Paulo, Brazil, 2012

\begin{tabular}{lcl}
\hline $\mathrm{dmft}$ & Number $(\mathrm{N})$ & Percentage $(\%)$ \\
0 & 61 & 67 \\
1 & 12 & 13.2 \\
2 & 8 & 8.8 \\
3 & 5 & 5.5 \\
4 & 3 & 3.3 \\
6 & 1 & 1.1 \\
12 & 1 & 1.1 \\
\hline TOTAL & 91 & 100 \\
\hline
\end{tabular}


Table 2 - Association between Body Mass Index (BMI) and dental caries in preschoolers. Araçatuba, São Paulo, Brazil, 2012

\begin{tabular}{|c|c|c|c|c|c|c|c|c|c|c|c|c|}
\hline & \multicolumn{2}{|c|}{ Thinness } & \multicolumn{2}{|c|}{$\begin{array}{l}\text { Ideal } \\
\text { Weight }\end{array}$} & \multicolumn{2}{|c|}{$\begin{array}{c}\text { Risk of } \\
\text { Overweight }\end{array}$} & \multicolumn{2}{|c|}{ Overweight } & \multicolumn{2}{|c|}{ Obesity } & \multicolumn{2}{|c|}{ Total } \\
\hline & $\mathrm{n}$ & $\%$ & $\mathrm{n}$ & $\%$ & $n$ & $\%$ & $\mathrm{n}$ & $\%$ & $n$ & $\%$ & $n$ & $\%$ \\
\hline $\mathrm{dmft}=0$ & 1 & 1.1 & 37 & 40.7 & 12 & 13.2 & 7 & 7.7 & 4 & 4.4 & 61 & 67 \\
\hline $\mathrm{dmft} \geq 1$ & 0 & 0 & 20 & 22 & 5 & 5.5 & 3 & 3.3 & 2 & 2.2 & 30 & 33 \\
\hline$\overline{T O T A L}$ & 1 & 1.1 & 57 & 62.7 & 17 & 18.7 & 10 & 11 & 6 & 6.6 & 91 & 100 \\
\hline
\end{tabular}

Chi-square $=0.1447 ; p=0.7036$

was found a lower value of the index and a higher percentage of caries-free children, probably because children under 5 years of age were included and consequently had their teeth exposed to the oral environment for a shorter time.

Excess weight and obesity are found with great frequency from the age of 5 up, in all socio-economic groups and regions of Brazil. Overweight affects more than $30 \%$ of children between 5 and 9 years of age and about $20 \%$ of the population between 10 and 19 years of age ${ }^{13}$. In another Brazilian study conducted in Recife, PE, Brazil in 1999, was observed a high frequency of weight disorders in children and adolescents. The prevalence of overweight and obesity in children was $26.2 \%$ and $8.5 \%$, respectively ${ }^{14}$.

These data corroborate the present work, because $1 / 3$ of the studied children, albeit in a younger age group, were in the most concerning BMI stratification for quality of life.

Eating habits are an important etiologic factor for both obesity and tooth caries, since the amount of sugar intake and frequency of ingestion are factors involved in its etiology ${ }^{15}$.

Different studies (cross-sectional ${ }^{16}$ and prospective cohort ${ }^{17}$ ) in different countries showed positive correlation between dental caries and BMI.

In contrast, a cross-sectional study of Iranian children showed no association between weight, height and dental caries ${ }^{18}$. This result corroborates the finding of the present study where no association was found between BMI and dental caries. A possible explanation is that although both obesity and dental caries are often attributed to the high intake of carbohydrates and sugar, the true etiology of these diseases is much more complex and multifactorial ${ }^{9-10,19}$. An example of that may be the Xavier et al. ${ }^{20}$ study which demonstrated that people living in low socioeconomic conditions have the worst oral health conditions due to the exposure to risk factors interfering with their quality of life.

Another possible cause is the rapid BMI changes in children as they grow and these changes do not relate strictly to body fat ${ }^{19}$. Also the different educational and preventive measures undertaken to deal with dental caries in Brazil, and the small sample size may have led to lack of association between these diseases ${ }^{10}$.

In other studies ${ }^{21-22}$ findings the association was inverse, where individuals with higher caries experience had a lower Body Mass Index (BMI). Malnutrition may be associated with increased susceptibility to dental caries by the impaired composition and saliva secretion ${ }^{21}$. Ayhan et al. ${ }^{22}$ observed association between nutritional status and caries in early childhood, where children with low-birth weight were more likely to have serious problems of dental caries compared to children with normal weight.

A systematic review ${ }^{23}$ analyzed evidence for the association between obesity and dental caries, but the study did not find sufficient evidence for the association and did not clarify the possible role of diet and other possible factors of this association.

In Brazil, further research should be carried out with larger samples in order to try to elucidate the possible relationship between these diseases. Currently, it is also critical that dental professionals be aware of the risk that overweight brings to patient's health and seek to sensitize and motivate them to adopt healthy eating habits in order to prevent the occurrence of dental caries as much as obesity.

It is also necessary to implement intervention programs and create a system of food and nutrition surveillance for children at this age, since this period is the most conducive to acquiring good habits and behaviors.

\section{References}

1. World Health Organization (WHO). Obesity: preventing and managing the global epidemic: report of a WHO consultation. Geneva: World Health Organization; 2000 [cited 2013 Apr 26]. Available From: http://whqlibdoc. who.int/trs/WHO_TRS_894.pdf?ua=1.

2. World Health Organization (WHO). Obesity and overweight, 2012 [cited 2013 Apr 26]. Available from: http://www.who.int/mediacentre/factsheets/ fs311/en.

3. Mello ED, Luft VC, Meyer F. Childhood obesity: towards effectiveness. J Pediatr (Rio de Janeiro). 2004; 80: 173-82.

4. Silva CM, Basso DF, Locks A. Feeding in infancy: approach for oral health promotion. Rev Sul-Bras Odontol. 2010; 7: 458-65.

5. Souza Filho MD, Carvalho GDF, Martins MCC. Consumption of sugarrich foods and dental caries in preschool children. Arqu Odontol. 2010; 46: 152-9.

6. Ramos M, Stein LM. Development of children's eating behavior. J Pediatr. (Rio de Janeiro). 2000; 76: S229-37.

7. World Health Organization (WHO). Oral health surveys: basic methods. 4th ed. Geneva: World Health Organization; 1997 [cited $2013 \mathrm{Apr}$ 26]. Available from: http://www2.paho.org/hq/dmdocuments/2009/ OH_st_Esurv.pdf.

8. Brazilian Pediatric Society. Nutritional evaluation of children and teenagers - Orientation Manual. São Paulo: Brazilian Pediatric Society. Nutrology Department; 2009 [cited 2013 Apr 26]. Available from: http:// www.sbp.com.br/pdfs/MANUAL-AVAL-NUTR2009.pdf.

9. Losso EM, Tavares MC, da Silva JY, Urban CA. Severe early childhood caries: an integral approach. J Pediatr (Rio de Janeiro). 2009; 85: 295300.

10. Cypriano S, Hugo FN, Sciamarelli MC, Tôrres LHN, Sousa MLR, Wada RS. Factors associated with the incidence of dental caries among schoolchildren living in a municipality with low prevalence of dental caries. Cienc Saude Colet. 2011; 16: 4095-106.

11. Brazil. Ministry of Health - Department of Health Care. Department of Health Surveillance. Department of Primary Care - General Coordination of Oral Health. SB Brazil 2010: National Survey on Oral Health: Key Findings. Brasilia: Ministry of Health; 2011 [cited 2013 Apr 26]. Available 
from: http://bvsms.saude.gov.br/bvs/publicacoes/pesquisa_nacional_saude_bucal.pdf.

12. Amaral RC, Batista MJ, Meirelles MPMR, Cypriano S, Sousa MLR. Dental caries trends among preschool children in Indaiatuba, SP, Brazil. Braz J Oral Sci. 2014; 13: 1-5.

13. Brazilian Institute of Geography and Statistics (IBGE). POF 2008-2009: Malnutrition falls and Brazilian children's weight exceeds international standard, 2012 [cited 2013 Apr 26]. Available from: http://www.ibge.gov. br/home/presidencia/noticias/noticia_visualiza.php?id_noticia=1699\&id_ pagina=1.

14. Balaban G, Silva GAP. Overweight and obesity prevalence in children and adolescentes from a private school in Recife. J Pediatr (Rio de Janeiro). 2001; 77: 96-100.

15. Traebert J, Moreira EAM, Bosco VL, Almeida, ICS. Changing from breastfeeding to family feeding: a common problem for both obesity and dental caries. Rev Nutr. 2004; 17: 247-53.

16. Honne T, Pentapati K, Kumar N, Acharya S. Relationship between obesity/ overweight status, sugar intake and dental caries among adolescents in South India. Int J Dent Hyg. 2012; 10: 240-4.

17. Alm A, Fahraeus C, Wendt LK, Koch G, Andersson-Gare B, Birkhed D. Body adiposity status in teenagers and snacking habits in early childhood in relation to approximal caries at 15 years of age. Int J Paediatr Dent. 2008; 18: 189-96.

18. Sadeghi M, Lynch CD, Arsalan A. Is there a correlation between dental caries and body mass index for age among adolescents in Iran? Community Dent Health. 2011; 28: 174-7.

19. World Gastroenterology Organization (WGO). World Gastroenterology Organization Global guideline: obesity. Munich: World Gastroenterology Organization; 2009 [cited 2013 Apr 26]. Available from: http://www. worldgastroenterology.org/assets/export/userfiles/Obesity-Master\%20 Document $\% 20$ for $\% 20$ Website.pdf.

20. Xavier A, Carvalho FS, Bastos RS, Caldana ML, Bastos JRM. Dental caries-related quality of life and socioeconomic status of preschool children, Bauru, SP. Braz J Oral Sci. 2012; 11: 463-8.

21. Johansson I, Lenander-Lumikari M, Saellstrom AK. Saliva composition in Indian children with chronic protein-energy malnutrition. J Dent Res. 1994; 73: 11-9.

22. Ayhan $\mathrm{H}$, Suskan $\mathrm{E}$, Yildirim $\mathrm{S}$. The effect of nursing or rampant caries on height, body weight and head circumference. J Clin Pediatr Dent. 1996; 20: 209-12.

23. Silva AER, Menezes AMB, Demarco FF, Vargas-Ferreira F, Peres MA. Obesity and dental caries: systematic review. Rev Saude Publica. 2013;

47: 799-812. 